\title{
Acute Bilineal Leukemia in Remission
}

National Cancer Institute

\section{Source}

National Cancer Institute. Acute Bilineal Leukemia in Remission. NCI Thesaurus. Code C159231.

Acute bilineal leukemia not growing; responding to treatment. 